\title{
DOUBLE AORTIC ARCH
}

\author{
BY
}

CHARLES E. SNELLING, M.B.,

AND

I. H. ERB, M.B.

(From the Hospital for Sick Children, and the Department of Pædiatrics, University of Toronto, under the direction of Dr. Alan Brown.)

Double aortic arch is a comparatively rare anomaly which has been discovered usually in the dissecting room or at autopsy. Most of the recorded cases have had symptoms of constriction of the œsophagus and trachea, resulting in death from broncho-pneumonia at an early age, but occasionally the condition has given rise to no unusual phenomena, and has been found in adult subjects. We report here a case of double aortic arch, which was diagnosed clinically as persistent right aortic arch with constriction of the œsophagus and trachea.

\section{Case report.}

M.S., a four months white female, was admitted to hospital on November 4th, 1932. The parents had noticed that the infant had breathed noisily since birth, and had had severe blue spells two weeks and one week prior to admission. The family history was of no consequence; the gestation was nine months; the birth weight was $6 \mathrm{lb}$; the labour and neonatal periods were not abnormal.

The infant was breast fed. There was some regurgitation during and after feeding. Frequently the child had to stop nursing to get its breath. No codliver oil or orange juice had been given, but the child had been exposed to the summer sun. The noisy, rattling breathing, which was present from birth, had not been unduly alarming until two weeks before admission, when the child had a severe blue spell. Artificial respiration was necessary as the child was unable to get its breath for some time. A similar attack occurred one week later. The mother noted that the child had difficulty in drawing the air into the chest, because there was a recession of the ribs and abdomen when the child took a breath. This was made worse by excitement and crying. Nursing was frequently interrupted so that the child might get its breath. No inspiratory crow or convulsions had been observed. A brassy, dry, hacking cough had been present since two months of age.

On admission the child did not appear severely ill, though it was obviously breathing with difficulty. The throat was red: the right ear drum was bulging, and paracentesis was done. Difficulty with respiration, especially inspiration, was evident from the indrawing of the chest wall and an audible inspiratory stridor. The breath sounds were transmitted from the larger passages and were loud and wheezy in type. No other abnormal physical findings were noted. Direct laryngoscopy revealed nothing abnormal in the vocal cords, larynx or trachea as low as the third tracheal ring.

For the first 10 days in hospital varying pyrexia up to $104^{\circ}$, due to the upper respiratory infection, prevented any further investigation other than a roentgenogram of the chest, which revealed some peribronchial infiltration Two weeks after admission, when the infection seemed to be clearing, the child had a series of severe attacks of blueness for which artificial respiration 
was required. It was noted that these occurred during or following feedings. Coincident with this the upper respiratory infection flared up. Barium was given and a roentgenogram of the œsophagus was made, showing a constric-

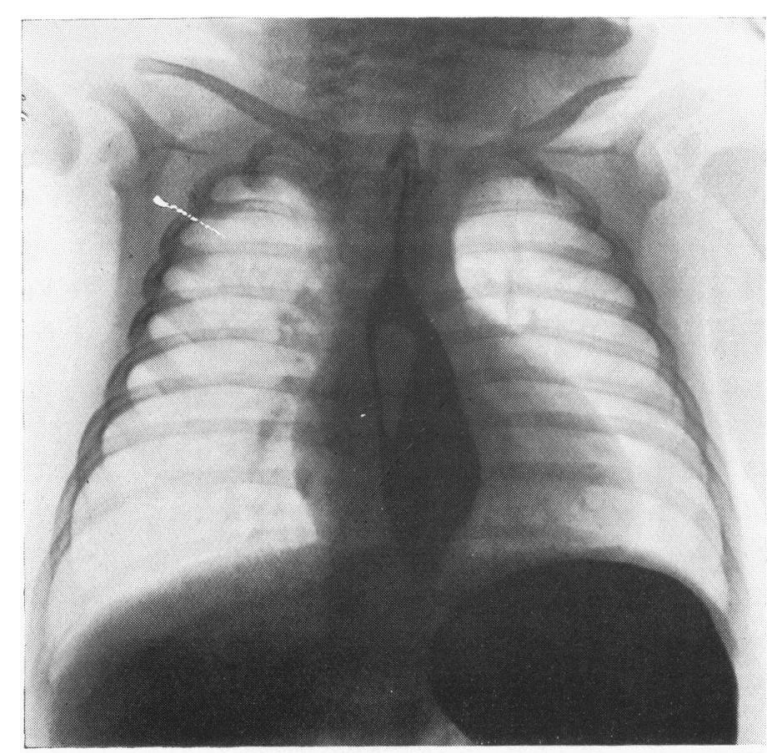

FIG. 1.

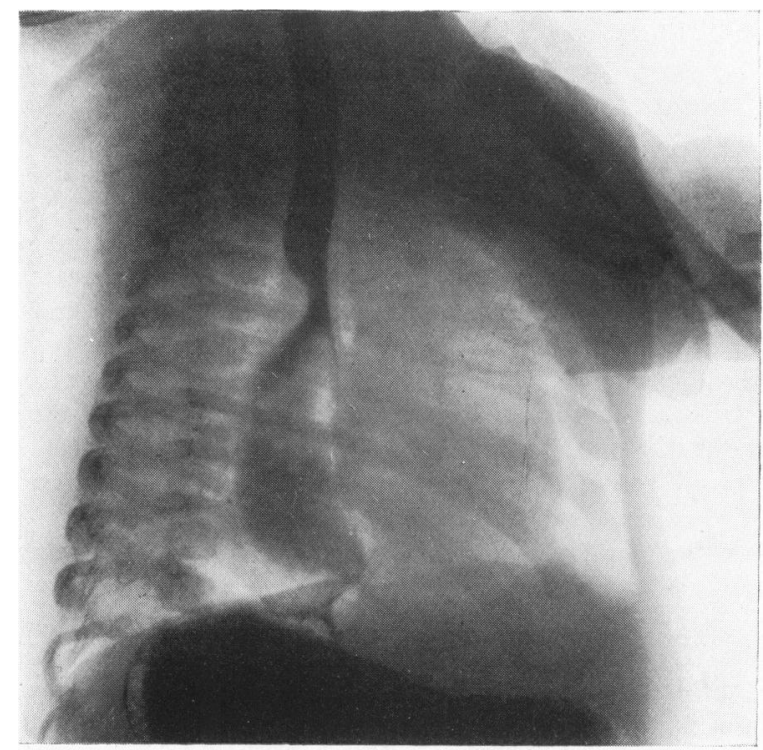

FIG. 2.

Radiograms showing a constriction of the osophagus opposite the bodies of the third and fourth dorsal vertebræ.

tion opposite the bodies of the third and fourth dorsal vertebræ (Fig. 1 and 2). Below this was a ballooning of the osophagus similar to that seen in 
cardiospasm. The similarity of the roentgenogram and history to those of right aortic $\operatorname{arch}^{1}, 2$, led us to advance the diagnosis of persistent right aortic arch, causing constriction of the trachea and cosophagus.

The upper respiratory infection progressed, broncho-pneumonia developed, and the infant died one month after admission.

Post-mortem report. The body was fairly well developed and poorly nourished. The skin was dry, pale, hung rather loosely and showed no superficial lesions. There was no superficial glandular enlargement.

The abdominal cavity and viscera appeared normal. In the thorax both pleural cavities were free from fluid, adhesions and pus. The thymus was normal.

The pericardial sac contained a normal amount of clear, straw-coloured fluid. The pericardium appeared healthy. The heart was not enlarged, and the valves and chambers were normal. It contained a small amount of dark red, poorly-clotted blood. The superior and inferior venæ cavæ entered the right auricle in the usual manner. The pulmonary artery was healthy and arose from the right ventricle dividing into right and left pulmonary arteries. The pulmonary veins entered the left auricle showing no abnormalities.

The aorta is described below with the trachea, bronchi, œsophagus and stomach. The lungs were salmon-pink and crepitant anteriorly. Posteriorly both showed considerable diminution in crepitation, especially in the lower lobes where none was elicited. In this area the lung was quite firm and of a greyish-red, mottled appearance. The bronchial glands were enlarged and red.

The liver, gall-bladder, spleen and pancreas appeared normal. The kidneys and genito-urinary tract were healthy. The duodenum, small and large intestine, were healthy throughout. There were no abnormalities of the mesentery. The scalp and calvarium were normal. The anterior fontanelle was depressed. The dura mater was smooth and pearly white. The lepto-meninges were not congested. The convolutions were well marked. The substance of the whole brain appeared normal. The ventricles were not dilated; they contained clear, colourless fluid. The intracranial venous sinuses were not thrombosed.

The right middle ear and mastoid antrum were filled with thick, yellowish pus. The right drum was opaque and had an opening in its posterior quadrant, which was covered over by pus. The left middle ear and mastoid antrum were similar to the right, except that the pus on this side was red. The opening in the left ear drum was still patent.

Aorta, trachea, bronchi, (esophagus and stomach. The aorta arose in the usual manner from the left ventricle passing upward, behind and to the right of the origin of the pulmonary artery. The aorta then turned posteriorly and slightly to the left. Three centimetres from its origin, in the portion running posteriorly and slightly obliquely to the left, the aorta divided into two. One branch passed to the left of the trachea and oesophagus, the other to the right of these structures. These two divisions united again posterior to the cesophagus and slightly to the left of the mid-line, forming the descending aorta which coursed caudalwards on the left side of the vertebral column in the usual manner. The osophagus and trachea were thus enclosed in a vascular ring formed by the reduplication in the transverse portion of the arch of the aorta. The right division of the aortic arch gave origin to the right subclavian and right common carotid arteries; the left division gave origin to the same vessels on the left side. The obliterated ductus arteriosus, coming from the pulmonary artery, joined the left branch of the aorta just beyond the subclavian artery.

The measurements were as follows: The circumference of the ascending aorta was $2 \mathrm{~cm}$. The division of the aorta commenced $3 \mathrm{~cm}$. from the aortic valves. The right arch was $1.7 \mathrm{~cm}$. in length, the left was $1.5 \mathrm{~cm}$. The circumference of each of these arches was $1.5 \mathrm{~cm}$. 
The arterial ring formed by the reduplication of the transverse aortic arch encircled the osophagus midway between the pharynx and stomach. Above this level the cesophagus was dilated, having a diameter of $1.5 \mathrm{~cm}$. At the level of the vascular ring the œsophagus was $0.7 \mathrm{~cm}$. in diameter. Below the constriction it gradually increased to a diameter of $2 \mathrm{~cm}$. Where the œsophagus passed through the diaphragm it measured $1.2 \mathrm{~cm}$. in diameter. The cardiac: opening in the stomach showed no abnormal constriction. The stomach was small with a capacity of about $1 \mathrm{oz}$. The walls were comparatively thick due to contraction.

The larynx and upper portion of the trachea were normal. Just above the bifurcation the trachea passed through the arterial ring. At this point it lay directly anterior, and in close apposition, to the osophagus. These two structures were compressed together by the arterial ring, so that the trachea was flattened in its anteroposterior diameter. The œsophagus was pressing the muscular portion of the trachea forwards, so that the lumen was very small. This compression of the lumen was also present in the proximal portion of the right and left main bronchi.

The recurrent laryngeal nerve on either side hooked around the respective divisions of the aortic arch and passed upwards between the oesophagus and trachea to the larynx.

Culture of the lung grew pneumococcus type 19.

Pathological diagnosis: (1) Double aortic arch; (2) compression of trachea and œsophagus; (3) bronco-pneumonia (bilateral); (4) otitis media (bilateral).

Comment.-In this patient the vascular circle formed by the double aortic arch was constricting the trachea and osophagus. There was sufficient continual pressure to cause stridor from birth. A brassy cough developed at two months of age, and may have been due to the relative increased compression of the trachea, or to pressure on, or irritation of, the recurrent laryngeal nerves. With the taking of larger quantities of food this partial occlusion was further emphasized, so that severe attacks of cyanosis were observed. Roentgenograms made to account for this revealed the constriction of the esophagus, which suggested some anomaly of the aortic arch.

Blackford, Davenport and Bayley ${ }^{1}$ presented the first report in English of a case of right aortic arch recognized during life. It was from their report, and from a similar case seen at the Boston Children's Hospital ${ }^{2}$, that this type of anomaly was considered in our case.

Through the kindness of Dr. K. D. Blackfan we have the report of the case at the Boston Children's Hospital ${ }^{2}$. The infant presented a history of choking and difficulty in breathing from birth to the time of admission at five months of age. There was no vomiting, but some refusal of food and apparent difficulty in swallowing. The roentgenogram of the œsophagus showed it to be pushed forward at the level of the third and fourth dorsal vertebræ. The infant died of broncho-pneumonia. Post mortem a vascular circle about the trachea and œsophagus was found, which was formed by a right aortic arch that passed above the right bronchus and behind the œsophagus, uniting by the obliterated ductus arteriosus with the pulmonary artery, thus completing the ring.

In the report by Blackford ${ }^{1}$ diagrammatic tracings and the original roentgenogram show a displacement of the œsophagus to the left at the level 
of the third and fourth dorsal vertebræ, though there were no signs or symptoms of dysphagia or interference with respiration.

\section{Discussion.}

In an early stage of the development ${ }^{3}$ of the vascular system the ventral aorta is given off from the cephalad portion of the heart, which at that stage has two chambers. This divides into two branches from each of which six aortic arches arise, passing dorsally to the bilateral dorsal aortæ, which as they pass caudad join to form a single trunk. A longitudinal septum develops in the heart, making four chambers, and the pulmonary aorta becomes separated from the ventral aorta. The vascular system lengthens and curves are formed to take up the elongation. The aorta courses to the right from its origin in the left ventricle in this stage. Due to the direction of the stream, the slack produced by the elongation of the vascular system, body curvature and possibly some other mechanical factors, the flow tends to be greater in certain portions, so that some of the arches are more adapted to carry the blood and these enlarge ${ }^{1}$ : the others disappear. The fourth left bronchial arch normally becomes the main stream in all mammals, and forms the transverse portion of the arch of fully developed aorta ${ }^{3,4}$. There is some question regarding the fifth bronchial arch. By some it is believed to unite with the fourth in the formation of the arch of the aorta. The third arch on either side becomes the internal carotid artery. The fourth arch on the right becomes the subclavian artery, and the right primary division of the ventral aorta forms the innominate artery. The left pulmonary artery is joined to the descending aorta by the ductus arteriosus, which is the vestige of the sixth bronchial arch.

In birds, due to mechanical factors acting differently, the tendency of blood flow is not the same. The fourth arch on the right side is maintained and the left atrophies. In reptiles both fourth arches are maintained ${ }^{3}$. Both of these forms of development, which are normal for the species mentioned, are found in humans, the type which is normal for birds occurring much more frequently than the reptilian form. It is the latter. type which was found in the case reported here. The development of the aortic arches in the embryo pig and chick are beautifully described by Congdon and Wang ${ }^{4}$.

In 1930, Rochdestwenskig ${ }^{5}$, searching the literature, collected 12 cases of double aortic arch. Sprong and Cutter ${ }^{6}$ collected 15, and also in the same year Lockhart ${ }^{7}$ found 19 and adds one of his own.

Lockhart states that most are found in children dying within seven months of age, exhibiting stridor, cyanosis, dysphagia and pulmonary infection. In those that survive to adult life one or other arch is much smaller, usually being only a fibrous band, or barely pervious, and rarely causing symptoms. Rochdestwenskig's patient was, however, a man of 55 , in whom symptoms began shortly before death.

Sprong and Cutter, in collecting from the literature 100 cases of the anomalies of the arch of the aorta with the right arch present, found that 
simple right aortic arch with variations of vessel origin comprised 39 per cent., double aortic arch 15 per cent. and situs universus the remainder. Poynter ${ }^{8}$ found that double aortic arch accounted for $\mathbf{2 \cdot 2}$ per cent. of the reported cases of anomaly of the arch of the aorta.

Persisting double aortic arch forms an arterial ring through which certain structures pass. These have been the trachea alone, trachea and

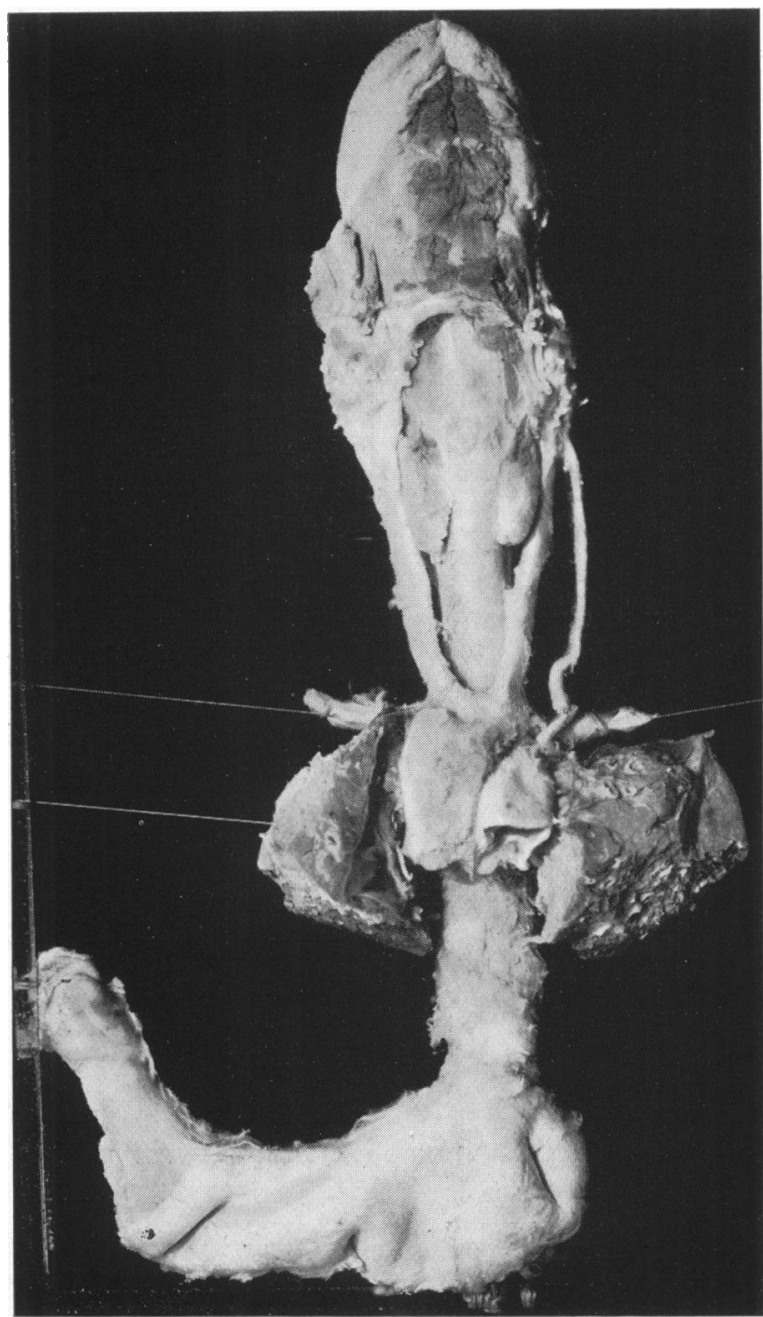

FIG. 3.-Photograph of specimen : anterior view.

œsophagus, and the thoracic duct and pulmonary vessels have been included. Both recurrent laryngeal nerves usually hook around the respective aortic arches ${ }^{5,6,7,8}$. The usual type encloses the trachea and œsophagus. It is believed that the case with the trachea alone may not have been a true double aortic arch, but rather due to some anomalous artery from the arch of the aorta.

Assman ${ }^{9}$ described first the diagnosis during life of right aortic arch in 1918. Since then there have been others using his criteria who have made 
the diagnosis. Renander ${ }^{10}$ found an abnormal kinking of the osophagus after the giving of barium in a patient with dysphagia, and made the diagnosis. He Iater reconstructed the anomaly in plaster-of-Paris from his knowledge gained by the roentgen studies. Blackford et al. diagnosed the condition in a child of nine years, who was still alive at the time of the report.

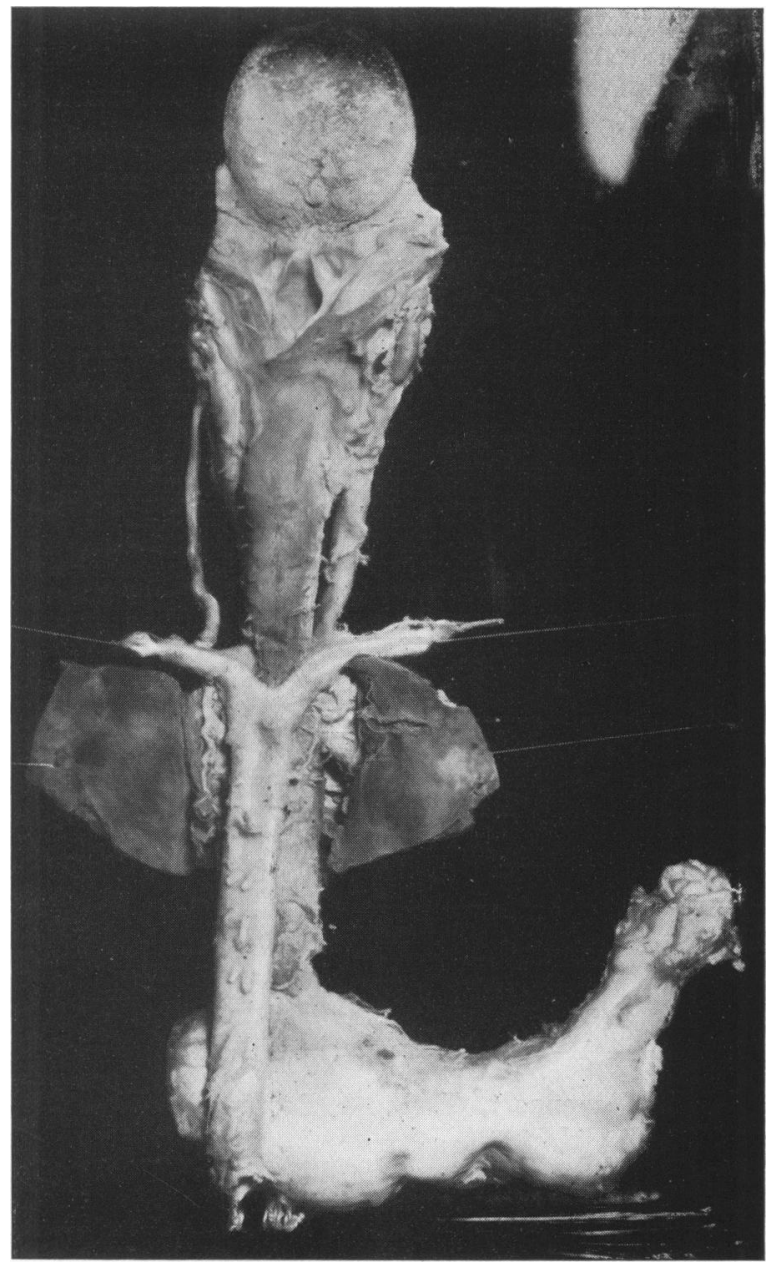

FIg. 4.-Photograph of specimen: posterior view.

The criteria for the diagnosis in all these reports is the finding of a kink in the œsophagus seen with barium by means of roentgen rays. The kink is at the level of the third and fourth dorsal vertebræ, showing a displacement of the osophagus to the left and forward, then downward, backward, and finally to the right, continuing down to the stomach in line with the upper segment. In none of these was there a vascular circle or a complete double aortic arch. In the case here reported the line of the œsophagus did not deviate from its general direction (Fig. 3 and 4). 
The kinking was more of the nature of a constriction at the level of the third and fourth dorsal vertebræ. This, taken with the dysphagia, cough, stridor and choking spells, indicated that there was a constriction of the œsophagus and trachea rather than a deviation due to the right aortic arch or some tumour mass. In the case from the Boston Children's Hospital the vascular arch was completed by the ductus arteriosus and pulmonary artery with a right aortic arch.

Bronchoscopy and œesophagoscopy were to have been attempted in our patient, but due to the respiratory infection this was not carried out. These might have shown a pulsation on all sides at the level of the constriction.

The diagnosis of constriction due to some form of vascular circle can be made clinically. To be more specific, however, and to state the exact type of anomaly, seems to be impossible. This is of importance, for if the anomaly were recognized surgical measures might hold some hope if the exact type were known. In these cases the prognosis is poor when symptoms start early in life ${ }^{7}$, and any measure that holds some hope for them is worth while attempting.

In anomalies of the aorta with a vascular circle about the cesophagus and trachea, the osophagus is constricted rather than deflected to the left. Roentgenologically, this is the distinguishing factor from the simple right aortic arch. This, with the symptoms of constriction of the œsophagus and trachea, make up the picture of vascular circle.

\section{Summary.}

A case of double aortic arch with clinical, roentgen and anatomical data is here reported. The difference in the roentgen picture from simple right aortic arch is discussed. A review of the embryology and recent literature is given. A short summary of a similar case from the Boston Children's Hospital is included.

\section{REFERENGES.}

1. Blackford, L. M., Davenport, T. F., \& Bayley, R. H., Am. J. Dis. Child., Chicago, 1932, XLIV, 823.

2. Blackfan, K. D., Report from Dr. Blackfan's Clinic, Boston Children's Hospital.

3. Bailey \& Miller, Textbook of Embryology, N.Y., 1916, .Ed. 3.

4. Congdon, E. D., \& Wong, H. W., Am. J. Anat., Philad., 1926, XXXVII, 499.

5. Roschdestwenskig, K. G., Anat. Anz., Jena, 1929-30, LXVIII, 145.

6. Sprong, D. H., \& Cutter, N. L., Anat. Rec., Philad., 1930, XLV, 365.

7. Lockhart, R. D., J. Anat, Camb., 1929-30, LXIV, 189.

8. Poynter, C. W. M., Univ. Nebraska Stud., Nebraska, 1916, XVI, 229.

9. Assman, H., Klin Röntgendiag. d. inn. Erkrankungen, Leipzig, 1924, Ed. 3, 103 (quoted from Ref. 1).

10. Renander, A., Acta Radiolog., Stockbolm, 1926, VII, 299. 